\title{
Exposure to respirable coalmine dust and incidence of progressive massive fibrosis
}

\author{
J F HURLEY, W P ALEXANDER, D J HAZLEDINE, M JACOBSEN, \\ W M MACLAREN
}

From the Institute of Occupational Medicine, Edinburgh EH8 9SU, UK

\begin{abstract}
Data gathered since 1953 concerning more than 30000 coalminers while employed at 24 collieries in England, Scotland, and Wales have been used to study the incidence of progressive massive fibrosis (PMF) in working coalminers. Results refer to 52264 approximately five year intervals when the miners were at risk of an attack of PMF. One objective of the present study was to describe how the five year attack rate of PMF was related to miners' age, colliery, and simple pneumoconiosis category at the start of the periods at risk. The main objective was to estimate the relation between exposure to dust and incidence of PMF and to examine how this relation changes in the presence of coalworkers' simple pneumoconiosis (CWSP). Film readings, in some cases based on clinical assessments only, showed 462 attacks of PMF over the five year risk periods. The men concerned had experienced higher cumulative exposures to dust than their colleagues of similar age at the same collieries, a result found at 65 of the 68 age colliery groups where an attack had occurred. The association was highly significant statistically. Simple pneumoconiosis clearly predisposed to PMF, with five year attack rates of $13.9 \%, 12 \cdot 5 \%, 4.4 \%$, and $0.2 \%$ among men with categories $3,2,1$, and 0 respectively at the start of the risk periods. Once simple pneumoconiosis category 1 or more had been attained, those with higher cumulative exposure to dust were not at greater risk of an attack of PMF than other men with the same CWSP category. Among most miners, those with category 0 , however, the risks of an attack of PMF increased clearly with exposure. Risks of an attack were higher among older men irrespective of CWSP category. In addition, there were large colliery specific variations in incidence related to variations in the carbon content of the coal though not fully explained by them. It is concluded that cumulative exposure to respirable dust is the decisive central factor in the development of PMF. Its effect is primarily in causing simple pneumoconiosis category 1 or higher which predisposes to PMF, though the dust related incidence among men with category 0 is not negligible in view of the large numbers at risk. Continuation of the policy to minimise dust concentrations underground therefore seems the only secure strategy to limit, and eventually eliminate, PMF.
\end{abstract}

Progressive massive fibrosis (PMF) is an occupational lung disease of coalminers. It is identified (other than at necropsy) by the classification of chest radiographs where the presence of large opacities distinguishes PMF from coalworkers' simple pneumoconiosis (CWSP). Simple pneumoconiosis is a relatively mild disease which is not necessarily accompanied by impairment of lung function ${ }^{1-3}$ or high mortality. ${ }^{45}$ The presence of PMF is more serious, however, and is

Accepted 20 October 1986 associated with reduced breathing capacity ${ }^{1}$ and with increased mortality. ${ }^{45}$ Moreover (and as its name implies) PMF is inherently progressive, ${ }^{6}$ and so an understanding of the factors influencing its occurrence is important so that preventive measures may be planned sensibly.

Because PMF is an occupational lung disease, it is natural when studying its causes to examine especially the role of exposure to respirable coalmine dust. In the absence of quantitative data on miners' individual exposures to dust previous studies have considered increasing severity of simple pneumoconiosis, which 


\section{2}

is clearly related to dust, ${ }^{7}$ as an indirect, though imprecise, measure of exposure. ${ }^{8}$ Thus two separate studies have shown that risks of an attack of PMF increased with increasing category of simple pneumoconiosis, ${ }^{89}$ a finding that has been confirmed again recently, ${ }^{1011}$ and so indirectly established the fundamental role of exposure to dust.

The role of simple pneumoconiosis as a factor predisposing to PMF provided the best epidemiological evidence to date on dust as a cause of the disease. There was increasing evidence also, however, that presence or incidence of PMF could be related successfully to direct estimates of dust exposure. Attacks of PMF over a 10 year period were known to be associated with relatively high concurrent exposures to respirable dust, though it had not been possible to express the association in terms of an exposure response relation. ${ }^{9}$ A relation linking cumulative exposure to respirable dust and PMF was indicated in a subsequent study, ${ }^{12}$ and has been established clearly in a yet more recent report, ${ }^{11}$ though neither of these investigations set out to examine systematically the relation between exposure and PMF. Nevertheless, these various studies did establish that, using data from the Pneumoconiosis Field Research (PFR) in Britain, it may be possible to describe the role of dust in a way that is relevant to occupational health policy.

The present study draws on all available PFR data to realise this aim. Our primary objective is to estimate directly the relation of dust exposure to incidence of PMF and to show how this relation changes when the well established intermediate role of simple pneumoconiosis is taken into account.

Dust exposure and simple pneumoconiosis are but two of the factors known or believed to be related to PMF. For example, age related variations in incidence have been noted in some studies ${ }^{910}$ but not in all, ${ }^{8}$ and there are important regional variations in the patterns of incidence in Britain. ${ }^{10}$ The subsidiary objective of the present study is to describe also these age and regional patterns of PMF incidence, not only because of their intrinsic interest but also because they are likely to have a bearing on the main objective of estimating the relation of PMF to dust exposure.

\section{Subjects and methods}

The methods used in the PFR, of which this report is a part, have been described frequently and were reviewed in $1979 .{ }^{13}$ We summarise only those aspects of the available research data relevant to the present paper.

\section{COLLIERIES}

Six rounds of medical surveys, at approximately five
Hurley, Alexander, Hazledine, Jacobsen, Maclaren $\overline{\bar{z}}$ year intervals, were carried out at selected collieries in $\bar{z}$ the British coalfields between 1953 and 1977 inclusive. $\stackrel{\circ}{\circ}$ These collieries were chosen specifically to include examples of all of the major variations in mining $\stackrel{\text { ? }}{+}$ conditions in Britain. ${ }^{14}$

Twenty four pits included in the first round of sur- $\frac{\bar{\partial}}{\bar{D}}$. veys (PFR 1, 1953-8) were included again in PFR $2 \frac{\bar{\omega}}{\overline{0}}$ and PFR 3, with the completion of PFR 3 in $1968 \stackrel{\Phi}{\circ}$ marking the end of the first phase of the research. Ten collieries only were included in PFR 4 and PFR 5, and only two of these had been surveyed for a sixth ${ }_{-}^{\circ}$ time when the second phase of the research was ended $\vec{\omega}$ in 1977. For purposes of data description the $24 \mathrm{col}-\stackrel{\rho}{\circ}$ lieries were formed into 10 groups on the basis of ${ }^{\circ}$ geographical region and per cent carbon, which is one? important measure of the rank of the coal being $\stackrel{+}{+}$ mined. ${ }^{15}$

\section{MEN AT RISK}

The PFR was designed to include all industrial work-을 ers employed at the research collieries at the time of $\rightarrow$ medical surveys. In all, 53382 coalminers par-O ticipated. In order to examine new occurrences of $\frac{0}{0}$ PMF, however, the study was restricted in the first instance to $30534(57 \cdot 2 \%)$ who attended medical surveys on at least two occasions. Those recorded ase showing PMF at their earliest survey were further.v excluded. The remaining men were considered at risi until the latest PFR survey they attended or, for me who experienced an attack of PMF, until the earliest survey when the response was diagnosed. Thus the present study refers to occurrences of PMF identified while men were employed in the coal industry and $\underset{\Rightarrow}{\Rightarrow}$ does not examine incidence in ex-miners.

\section{PERSON-INTER VALS AT RISK}

The amount of relevant information available for men at risk varies, even among those at risk for the same length of time. This complication arises because ${ }^{3}$ of differences in individuals' patterns of survey atten- $\frac{}{3}$ dance. Consider, for example, two miners who attended PFR 1 and PFR 5. Suppose that one man also을 attended PFR 2, 3, and 4, and that the other did not. Then for the first man there is information on the occurrence or not of PMF in four separate five year 7 periods, whereas for the second man there is information about a single 20 year period only. More generally, it was possible to divide each man's total time at risk in the study into distinct and non-overlapping periods by considering the times between the pairs of successive medical surveys he attended. These periods, or person-intervals, were adopted as the basice unit of analysis in the study since for each such inter-市 val the man was at risk of an attack of PMF, and the $\stackrel{?}{+}^{+}$ study procedures were able to identify whether or not ${ }^{T}$ an attack did occur. The strategy is analogous to the 
well known person-years at risk approach in studies of mortality. ${ }^{1617}$ Note that each man's total time at risk gave rise to one person-interval fewer than the number of PFR surveys he attended; methods of analysis did not distinguish between intervals which refer to the same coalminer and those which refer to other men.

Of the 54395 person-intervals thus generated, $53011(97 \%)$ arose from miners' attendance at adjacent PFR surveys, and so refer to periods of approximately five years' duration. Results in this paper are restricted to these approximately five year intervals. Detailed validation of the data led to the exclusion of $747(1.4 \%)$ of the five year intervals, referring to 467 men whose work history information was considered unreliable. Thus the present analyses are based on a study group of 52264 approximately five year personintervals where the men concerned were at risk of an attack of PMF.

\section{AGE AND RADIOLOGICAL CLASSIFICATIONS}

Each miner's date of birth was recorded at every survey he attended, discrepancies being resolved during subsequent data processing. A full sized posteroanterior chest radiograph of each man was also taken at every survey attended.

Shortly after the surveys concerned, at least two of four medical officers in the research team read all films from PFR 1, PFR 2, and from some collieries of PFR 3 to provide an agreed ("definitive") classification of each radiograph. ${ }^{18}$ Earlier films from the same man were available for reference throughout. PMF was recorded as category A, B, C, or PMF undefined, whereas the classification of simple pneumoconiosis referred to the four major categories of CWSP only. ${ }^{19}$ No information was available on whether men reported as having no PMF had other diseases.

Films taken subsequently, including all from PFR 4 or later surveys, were classified clinically by any one of five or six doctors in the Coal Board's Radiological Service to provide assessments of PMF and CWSP on scales comparable with the earlier readings. ${ }^{20}$ The present paper considers only whether or not PMF was judged to be present on the basis of definitive or clinical classifications; the severity of the disease (A, $\mathrm{B}, \mathrm{C}$, or undefined) has not been examined.

\section{EXPOSURE TO RESPIRABLE DUST}

The systems used to obtain information on each man's exposure to respirable mixed coalmine dust comprised methods for obtaining work histories, for monitoring dust concentrations, and for linking time with concentrations to provide estimates of exposure. The approach, outlined in several reports, ${ }^{347911-14}$ was based on a system of occupational groups at the research collieries, so that within each group the men were exposed to similar dust concentrations. Groups were redefined or closed, and new groups formed, to reflect changes in the work of the colliery through time.

Histories of individuals' work at the research collieries from 1953 onwards were recorded as shifts worked per week (including overtime) in the various occupational groups. These data were supplemented at medical survey interviews to provide details of the men's other coalmining experience (before the research programme began or subsequently at nonresearch pits) and summarised as years and months worked in six main classes of coalmining activity. Times were converted to hours by assuming that one calendar year's employment was equivalent to 1740 hours at work.

Dust concentrations were monitored using sampling instruments close to the men throughout selected working shifts. On this basis the average concentrations of respirable coalmine dust, in gravimetric units, were determined for all occupational groups and five year inter-medical-survey periods. The standard thermal precipitator ${ }^{21}$ used in the first phase of the research provided particle count and not gravimetric measurements. Its dust sampling characteristics were related during a series of side by side instrument comparisons ${ }^{15}$ to those of the gravimetric sampler $^{22}$ used subsequently, and the earlier measurements were re-expressed in equivalent gravimetric terms.

There was no direct monitoring of the dust concentrations to which men were exposed before the research began or at non-research collieries subsequently. Separately for men at each research colliery and each period, the average concentrations to which they were exposed in each of the six broad classes of coalmining activity were estimated by assuming that dust concentrations elsewhere were similar to those at the research pit in the corresponding period, and that concentrations before the research were similar to those experienced during the first 10 years of monitoring.

Finally, the men's exposures to respirable coalmine dust in any inter-survey period were estimated by forming the product of an individual's time worked in any occupational group or broad class of coalmining activity with the corresponding average dust concentration, and summing appropriately. The exposure units are gramme hours per cubic metre of sampled air $\left(\mathrm{ghm}^{-3}\right)$.

\section{STATISTICAL METHODS}

Extensive tabulations and graphical analyses of the data were carried out using programs from BMDP Statistical Software. ${ }^{23}$ The results from these analyses 
Table 1 Number of single ISP (five year) man intervals at risk, and per cent showing new attacks of PMF, by colliery and age at th start of an interval; also, carbon content of coal, by colliery

\begin{tabular}{|c|c|c|c|c|c|c|c|c|c|c|c|}
\hline \multirow[b]{3}{*}{ Age (years) } & \multicolumn{11}{|l|}{ Colliery } \\
\hline & \multirow{2}{*}{$\begin{array}{l}\text { Warwick } \\
\\
C\end{array}$} & \multicolumn{2}{|c|}{ Northumberland } & \multicolumn{4}{|c|}{ Scotland } & \multicolumn{4}{|c|}{ Yorkshire } \\
\hline & & $D$ & $Z$ & $S$ & $J$ & $P$ & $O$ & $Q$ & $K$ & $X$ & $G$ \\
\hline \multirow{4}{*}{$\begin{array}{l}<35 \\
35-44\end{array}$} & 705 & 322 & 581 & 395 & 648 & 1287 & 637 & 1150 & 874 & 1310 & $918^{\infty}$ \\
\hline & 0.1 & 0 & 0 & 0 & 0 & 0 & 0 & 0 & $\begin{array}{l}0 / 4 \\
0\end{array}$ & 0.1 & 0 \\
\hline & 828 & 287 & 576 & 222 & 459 & 1206 & 555 & 858 & 760 & 999 & $656^{\circ}=$ \\
\hline & $0 \cdot 1$ & & $0 \cdot 2$ & 0 & 0 & 0 & 0 & $0 \cdot 1$ & 0.7 & 0.5 & $0 \vec{\omega}$ \\
\hline \multirow[t]{2}{*}{$45-54$} & 1262 & 376 & 473 & 325 & 427 & 1178 & 610 & 859 & 886 & 1163 & 572 హె \\
\hline & 0.5 & 0 & 0 & 0.3 & 0 & 0 & $1 \cdot 1$ & 0.7 & $1 \cdot 2$ & $1 \cdot 1$ & $0.7 \frac{\mathrm{O}}{8}$ \\
\hline \multirow[t]{2}{*}{$\geqslant 55$} & 603 & 110 & 140 & 127 & 150 & 304 & 214 & 260 & 271 & 308 & 207 므 \\
\hline & 0.7 & 0.9 & 0 & 0.8 & 0.7 & 0.3 & $3 \cdot 3$ & 0.4 & $1 \cdot 1$ & $4 \cdot 5$ & 1.93 \\
\hline \multirow[t]{2}{*}{ All ages } & 3398 & 1095 & 1770 & 1069 & 1684 & 3975 & 2016 & 3127 & 2791 & 3780 & $2353 \stackrel{\vec{A}}{\vec{A}}$ \\
\hline & 0.4 & $0 \cdot 1$ & $0 \cdot 1$ & 0.2 & 0.1 & 0 & 0.7 & $0 \cdot 3$ & 0.7 & 0.9 & $0.3 \overrightarrow{0}$ \\
\hline \multirow{2}{*}{$\begin{array}{l}\text { Carbon } \\
\text { content (\%) }\end{array}$} & & & & & & & & & & & ன் \\
\hline & $81 \cdot 8$ & $84 \cdot 0$ & $84 \cdot 1$ & $81 \cdot 9$ & $82 \cdot 5$ & $84 \cdot 1$ & $85 \cdot 4$ & $81 \cdot 1$ & $84 \cdot 7$ & $85 \cdot 2$ & 85.5 고 \\
\hline
\end{tabular}

were used in formulating a series of multiple logistic regression equations $\mathrm{s}^{24}$ to represent the probability of a PMF attack as a function of various combinations of explanatory variables. Maximum likelihood estimation was carried out using the BMDP logistic regression program and the generalised linear model facilities of the GENSTAT statistical package, version 4.04. ${ }^{26}$ Chi squared tests based on the differences in maximised log likelihood ${ }^{24}$ (or equivalently, deviances ${ }^{25}$ in nested models) were used to assess the statistical significance of groups of variables. The estimated variance-covariance matrices of the fitted parameters were also used in assessing the statistical significance of individual characteristics.

Because the maximum likelihood estimation of logistic models is iterative, and so is time consuming with large sets of data, the logistic regression analyses were restricted to subsets of the available observations. All cases of PMF, and random samples of non-cases, sometimes stratified according to category of CWSP, were included in these analyses. The use of ordinary logistic regression methods for analysing the resulting (unmatched) case-control data is now wel established. ${ }^{27}$

When the probabilities of inclusion of individuals within strata are known and independent, as they were in this study, results from case-control logistic analyses may be modified straightforwardly to estimate the same relations that would have been estimated by inclusion of all the data ${ }^{27}$ The appropriate adjustments (subtraction of $\log _{\mathrm{e}} 10$ from the fitted constant for strata where only a $10 \%$ sample of non-

Table 2 Mean dust exposures $\left(\mathrm{ghm}^{-3}\right)$ accumulated up to the start of the interval, by colliery and age at the start, and by presence ${ }^{\mathbb{D}}$ (r) absence of PMF at the end, for single ISP (five-year) man intervals

\begin{tabular}{llll} 
Colliery & & \\
\hline Warwick & Northumberland & Scotland & Yorkshire
\end{tabular}

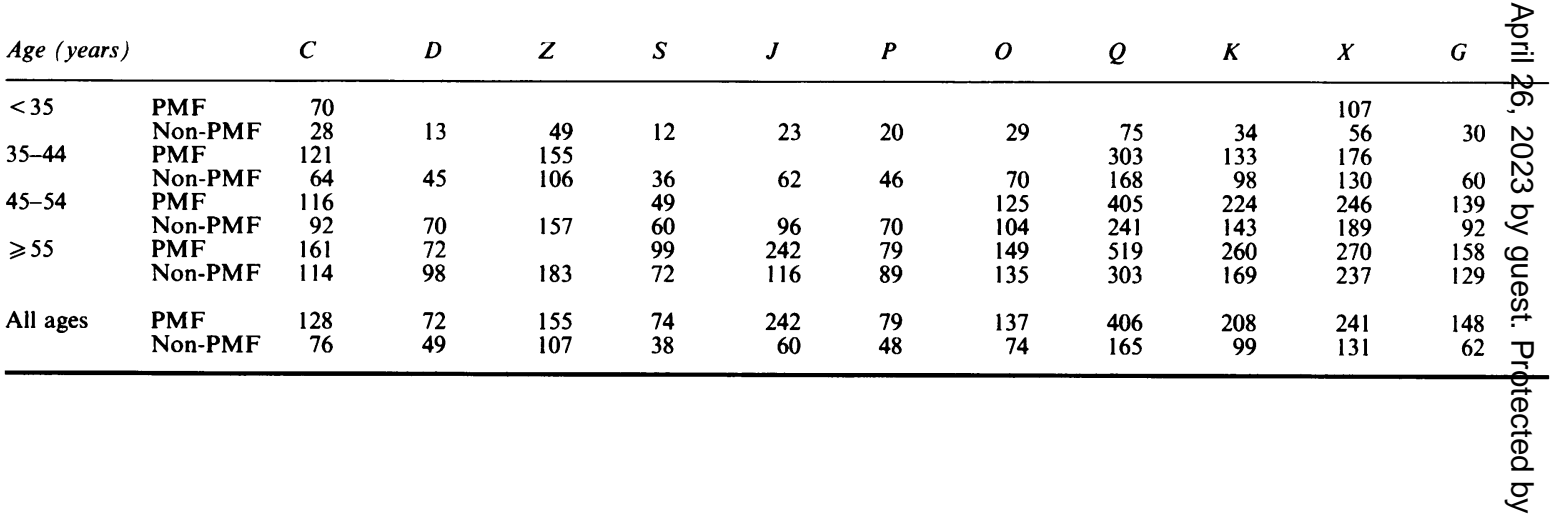




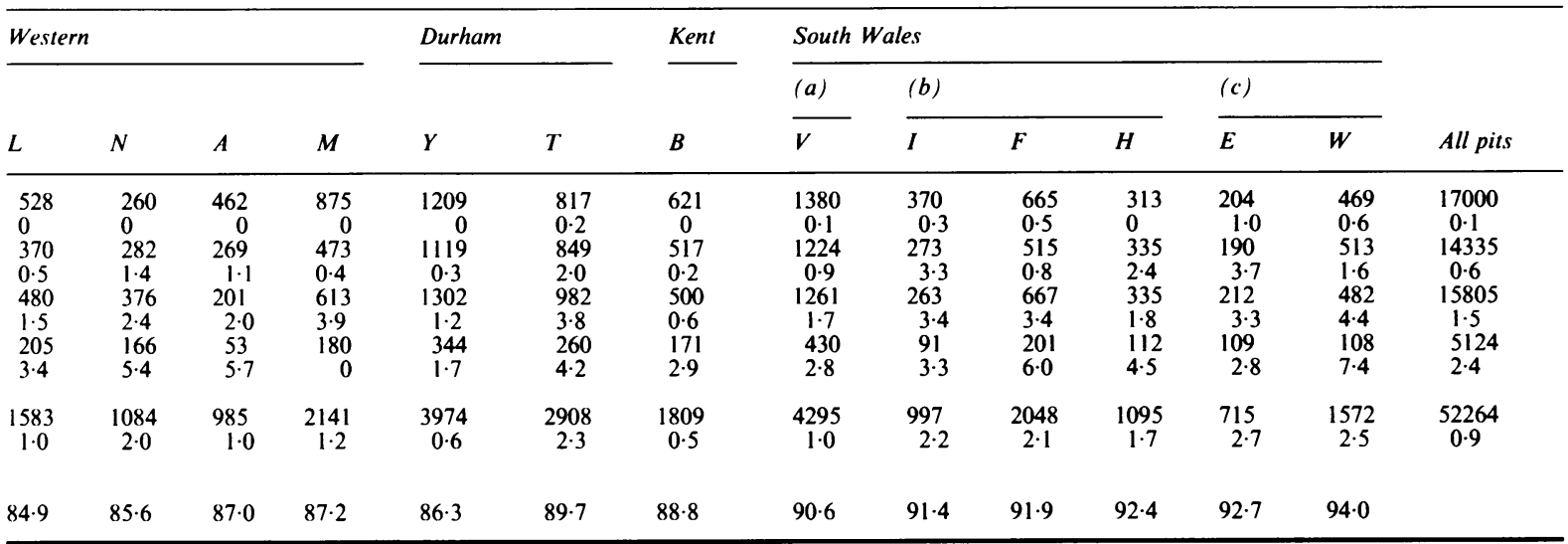

cases was included) were made and have been included in the results reported here.

\section{Results}

PMF occurred during 462 of the 52264 personintervals in the study, giving a crude attack rate of nine occurrences per 1000 men at risk, over approximately five year periods. The crude attack rate declined as the study progressed, from $1.0 \%$ among intervals starting at PFR 1 in the 1950 s to $0.4 \%$ among intervals which began with PFR 4 or PFR 5 in the 1970 s.

DATA DESCRIPTIONS, IGNORING SIMPLE

PNEUMOCONIOSIS

Table 1 shows that there were substantial numbers of person-intervals at risk at every colliery and throughout a range of ages. The incidence of PMF was associated with age, increasing from one occurrence per 1000 men at risk at age under 35 to 24 occurrences per 1000 at risk at age 55 or more over the subsequent, approximately five year, periods. Table 1 also shows that the crude incidence rate varied by colliery and was related to the coal rank and regional groupings of the pits, with higher incidence at high rank collieries, especially in south Wales. Similar rank related patterns of incidence are evident within age groups.

Table 2 shows unambiguously a relation between exposure to dust and subsequent incidence of PMF. The study data were partitioned into 96 groups by colliery and age, as in table 1 above. There were no new occurrences of PMF in 28 of these groups, characterised primarily by younger men at low rank col-

\begin{tabular}{|c|c|c|c|c|c|c|c|c|c|c|c|c|c|}
\hline \multicolumn{4}{|c|}{ Western } & \multicolumn{2}{|c|}{ Durham } & $\begin{array}{l}\text { Kent } \\
B\end{array}$ & \multicolumn{6}{|c|}{ South Wales } & All pits \\
\hline $\begin{array}{r}57 \\
209 \\
140 \\
263 \\
197 \\
367 \\
277\end{array}$ & $\begin{array}{r}65 \\
208 \\
134 \\
396 \\
207 \\
392 \\
221\end{array}$ & $\begin{array}{r}77 \\
395 \\
159 \\
300 \\
226 \\
505 \\
295\end{array}$ & $\begin{array}{r}36 \\
168 \\
105 \\
217 \\
185 \\
\\
236\end{array}$ & $\begin{array}{r}52 \\
210 \\
123 \\
265 \\
178 \\
303 \\
211\end{array}$ & $\begin{array}{r}147 \\
52 \\
159 \\
122 \\
255 \\
181 \\
313 \\
235\end{array}$ & $\begin{array}{r}40 \\
191 \\
96 \\
217 \\
159 \\
303 \\
190\end{array}$ & $\begin{array}{r}185 \\
57 \\
195 \\
149 \\
290 \\
206 \\
309 \\
235\end{array}$ & $\begin{array}{r}121 \\
51 \\
167 \\
121 \\
193 \\
161 \\
279 \\
174\end{array}$ & $\begin{array}{l}242 \\
102 \\
254 \\
230 \\
368 \\
281 \\
418 \\
299\end{array}$ & $\begin{array}{r}59 \\
199 \\
144 \\
251 \\
175 \\
193 \\
173\end{array}$ & $\begin{array}{r}97 \\
87 \\
213 \\
152 \\
216 \\
177 \\
234 \\
222\end{array}$ & $\begin{array}{r}171 \\
55 \\
214 \\
126 \\
260 \\
164 \\
249 \\
172\end{array}$ & $\begin{array}{r}158 \\
47 \\
194 \\
111 \\
260 \\
159 \\
293 \\
188\end{array}$ \\
\hline $\begin{array}{l}302 \\
147\end{array}$ & $\begin{array}{l}360 \\
155\end{array}$ & $\begin{array}{l}390 \\
141\end{array}$ & $\begin{array}{l}213 \\
110\end{array}$ & $\begin{array}{l}267 \\
127\end{array}$ & $\begin{array}{l}237 \\
132\end{array}$ & $\begin{array}{l}262 \\
103\end{array}$ & $\begin{array}{l}269 \\
144\end{array}$ & $\begin{array}{l}191 \\
110\end{array}$ & $\begin{array}{l}362 \\
211\end{array}$ & $\begin{array}{l}214 \\
132\end{array}$ & $\begin{array}{l}205 \\
151\end{array}$ & $\begin{array}{l}242 \\
119\end{array}$ & $\begin{array}{l}253 \\
112\end{array}$ \\
\hline
\end{tabular}


lieries. In 65 of the remaining 68 groups men who were classified as having PMF at the end of the ensuing five year period had, on average, higher dust exposures before the observation period than those who remained free of the disease. Each of the other three groups included only a single occurrence of PMF.

Corresponding data, based on dust exposures experienced during the study intervals themselves (and available on request), were less clear. Men in whom PMF was subsequently diagnosed experienced higher concurrent exposures than their counterparts in 52 of the 68 groups where comparisons were possible. The converse was true in 16 groups of men, scattered throughout the study but represented most strongly among older men in the south Wales collieries.

\section{DATA DESCRIPTIONS, INCLUDING SIMPLE PNEUMOCONIOSIS}

Table 3 shows that incidence of PMF was related strongly to a man's CWSP category at the start of the observation periods. The crude attack rate ranged from two per 1000 at risk among miners with category 0 CWSP to one in seven among those with category 3 , whereas the rate of about $4.4 \%$ among men with category 1 was sustantial also. It was necessary therefore to re-examine the role of dust exposure, age, and colliery related factors taking account of CWSP.

It is clear from the numbers at risk of an attack of PMF (table 3) that simple pneumoconiosis was more prevalent among older than among younger men. To some extent, therefore, the higher incidence of PMF in older men reflects this higher prevalence of CWSP. But other age related factors are important also, since the table shows further that even among miners with the same starting category of CWSP there is a clear association between PMF incidence and age.

It was also clear, and is shown in table 4, that men who had attained categories 1,2 , or 3 CWSP had on average experienced higher exposures to dust than had men with category 0 . But the relation between dust exposure and PMF, evident in table 2, is not due $\stackrel{\square}{\stackrel{2}{2}}$ solely to this fact. Table 4 shows that among men with category 0 CWSP, those who experienced an attack of PMF in the subsequent five year period had been $\bar{C}$ exposed to more dust at the start of the periods than had those not attacked. This relation between $\frac{\bar{\omega}}{\square}$ exposure and PMF is clearcut despite the low attack $\stackrel{\varnothing}{\Omega}$ rate of PMF in this group. Table 4, however, does not $\triangleq$ show a corresponding relation between amount of $\overrightarrow{ }$ dust exposure and PMF incidence once simple pneumoconiosis is already present.

As noted earlier, the crude attack rate of PMF $\stackrel{\omega}{\sigma}$ declined in the course of the research. Analyses by category of CWSP did not show this effect among 3 men with categories 2 or 3 . None of the 94 occurrences of PMF among category 0 men were found $\vec{\circ}$ during person-intervals starting from PFR 4 or PFR 5 , which accounted for $13 \%$ of the category 0 inter- 9 vals at risk. The position with regard to concurrent 0 exposure remained ambiguous, irrespective of category of CWSP, though among younger men 0 especially, concurrent exposures were higher in those who experienced an attack. Finally, men without simple pneumoconiosis exhibited colliery related vari- $\stackrel{\text { D }}{-}$ ations in incidence similar to those described already, $\overrightarrow{0}$ and to a lesser extent so did men with categories $1, \stackrel{\infty}{,}, \stackrel{\infty}{v}$ or 3 CWSP.

\section{LOGISTIC REGRESSION ANALYSES}

The regression analyses were also carried out in two $\frac{\partial}{D}$ stages. In the first instance CWSP was ignored in 0 order to estimate directly the overall relation between $\overrightarrow{\hat{O}}$ exposure and PMF. The logistic model was then extended to include CWSP in order to examine to what extent the relation of exposure and PMF is effected through presence of simple pneumoconiosis.

Analyses ignoring CWSP were based on a sample 3 of 5640 intervals, comprising all 462 where an attack of PMF had occurred, together with a $10 \%$ simple

Table 3 Number of single ISP (five year) man-intervals at risk, and number (\%) showing new attacks of PMF, by age and category of CWSP at the start of the interval

\begin{tabular}{|c|c|c|c|c|c|}
\hline \multirow[b]{2}{*}{ Category of CWSP } & \multicolumn{4}{|c|}{ Age (years) } & \multirow[b]{2}{*}{ All ages } \\
\hline & $<35$ & $35-44$ & $45-54$ & $\geqslant 55$ & \\
\hline 0 & 16753 & 13076 & 13173 & 4085 & 47087 \\
\hline 1 & $\begin{array}{c}2(0 \cdot 0) \\
190\end{array}$ & $\begin{array}{c}21(0 \cdot 2) \\
880\end{array}$ & $\begin{array}{l}42(0 \cdot 3) \\
1746\end{array}$ & $\begin{array}{l}29(0 \cdot 7) \\
687\end{array}$ & $\begin{array}{l}94(0 \cdot 2) \\
3503\end{array}$ \\
\hline 1 & $5(2 \cdot 6)$ & $34(3.9)$ & $79(4 \cdot 5)$ & $37(5 \cdot 4)$ & $155(4 \cdot 4)$ \\
\hline 2 & 53 & 323 & 755 & 291 & 1422 \\
\hline & $6(11 \cdot 3)$ & $30(9 \cdot 3)$ & $97(12 \cdot 8)$ & $45(15 \cdot 5)$ & $178(12 \cdot 5)$ \\
\hline 3 & $1(25 \cdot 0)$ & $\begin{array}{c}56 \\
7(12 \cdot 5)\end{array}$ & $\begin{array}{c}131 \\
17(13.0)\end{array}$ & $\begin{array}{l}61 \\
10(16 \cdot 4)\end{array}$ & $\begin{array}{c}252 \\
35(13.9)\end{array}$ \\
\hline All categories & $\begin{array}{l}17000 \\
14(0 \cdot 1)\end{array}$ & $\begin{array}{l}14335 \\
92(0 \cdot 6)\end{array}$ & $\begin{array}{l}15805 \\
235(1 \cdot 5)\end{array}$ & $\begin{array}{l}5124 \\
121(2 \cdot 4)\end{array}$ & $\begin{array}{l}52264 \\
462(0.9)\end{array}$ \\
\hline
\end{tabular}


Table 4 Mean dust exposures $\left(\mathrm{ghm}^{-3}\right)$ accumulated up to the start of the interval, by age and category of CWSP at the start, and by presence or absence of PMF at the end, for single ISP (five-year) man-intervals

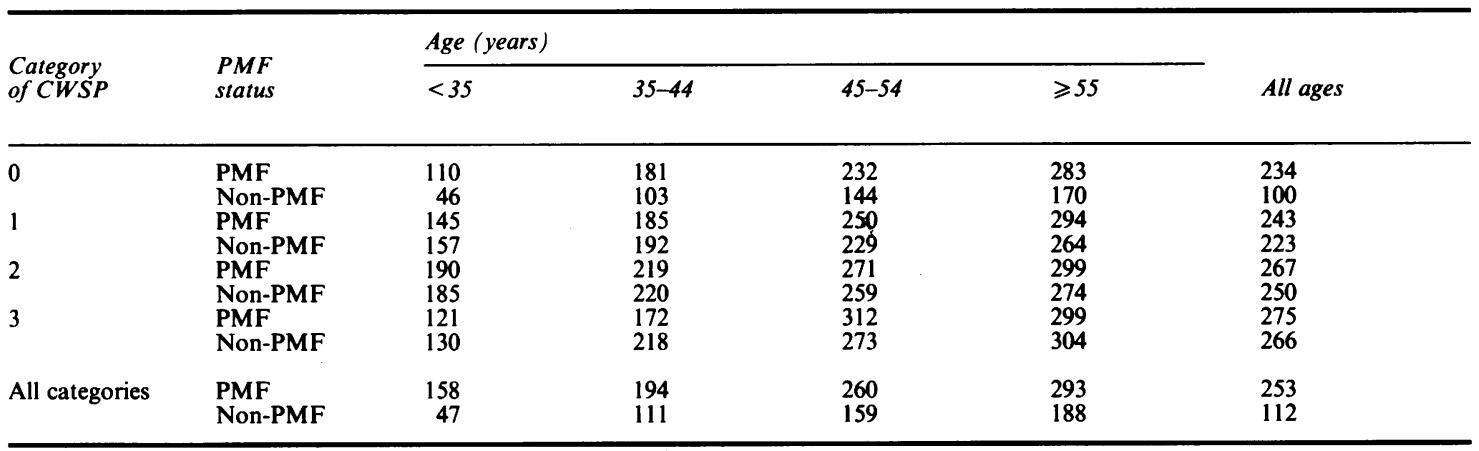

random sample of the remaining 51802 intervals. Most $(75 \%)$ of the intervals included started from PFR 1 or PFR 2. There were small variations in their duration (mean $5 \cdot 2$ years, SD $0 \cdot 8$ ). On average, the men concerned were aged 41 (SD 11) and had experienced $124 \mathrm{ghm}^{-3}$ dust exposure (SD 106) at the start of the periods included. Men from all 24 collieries were represented, with numbers per colliery ranging from 88 to 489 intervals.

Table 5 establishes clearly the statistical significance of the relation between exposure to dust and incidence of PMF. The magnitude of the association was estimated as an approximately fourfold increase in relative risk with a doubling of previous exposure. Not surprisingly, the risks of an attack were higher in longer study intervals. Age, which was related to previous exposure, was associated independently with incidence, implying a relative risk of 1.5 for each additional ten years of age. A downward trend in the survey specific risks was confirmed.

Table 5 Estimates of logistic regression coefficients, and associated tests of statistical significance, based on all 462 occurrences of PMF and a $10 \%$ random sample of non-occurrences

\begin{tabular}{llll}
\hline & \multicolumn{2}{l}{ Estimates } & \\
\cline { 2 - 4 } Variable* $^{\text {Coefficient }}$ & Test statistic & $p$ Value \\
\hline Constant & -6.28 & & \\
$\begin{array}{l}\text { Interval length } \\
\text { Cumulative dust }\end{array}$ & 1.980 & $\mathrm{t}=3.33$ & $<0.001$ \\
$\begin{array}{l}\text { exposure } \\
\text { Age }\end{array}$ & 2.000 & $\mathrm{t}=13.09$ & $\ll 0.001$ \\
Colliery & 0.0422 & $\mathrm{t}=4.80$ & $\ll 0.001$ \\
Survey round & & $\chi_{23}^{2}=206$ & $\ll 0.001$ \\
$\chi_{4}^{23}=15$ & $<0.005$ \\
\hline
\end{tabular}

*Units of measurement, and transformations used in the analysis, were as follows:

Variable

Units Transformation

Interval length

Cumulative exposure

Age

Years
ghm $^{-3}$

$\ln _{\mathrm{c}}(\mathrm{x})$

$\ln _{\mathrm{e}}(\mathbf{x}+1)$

$\dagger$ The constant shown refers to incidence from PFR 1 at colliery $W$, for a 45 year old man with $200 \mathrm{ghm}^{-3}$ exposure.
There remained unambiguous colliery related differences in PMF incidence. Further examination showed that these were related to, but not fully explained by, differences in the carbon content of the coal. The inclusion of concurrent dust exposure as a further explanatory variable did not improve the representation significantly $(\mathrm{t}=-0 \cdot 31)$.

To investigate the association between exposure to dust and PMF incidence in the presence of simple pneumoconiosis, the sample of 5640 intervals was augmented to one of 9984 intervals by including all those at risk whose starting category was CWSP 1, 2, or 3. Men in the augmented sample were older (mean 44, SD 11) and had been more heavily exposed to dust (mean 171, SD 117) than those in the smaller sample considered previously.

Analyses confirmed that, having taken exposure, age, colliery, and survey into account, there remained decisive differences in risk related to CWSP category $\left(\chi_{3}{ }^{2}>87, p \ll 0 \cdot 001\right)$. Results from further analyses are shown in table 6 . An exposure-response relation was established clearly among men with CWSP category 0 , where the estimated dust coefficient corresponds to a relative risk of about three among men with double the exposure of their colleagues. There was, however, no demonstrable association between exposure and PMF once CWSP category 1 or more had been attained: the three estimated dust coefficients were small and not significantly different from zero statistically (table 6). (It is interesting nevertheless that the estimated coefficient among men with category $3 \mathrm{CWSP}$ was negative.)

These patterns were confirmed in separate logistic analyses of data for men in each of the four categories of simple pneumoconiosis. They are illustrated also in fig 1 , where the risks have been standardised for convenience of display relative to values of $200 \mathrm{ghm}^{-3}$ exposure, category $1 \mathrm{CWSP}$, and colliery W. Note that whereas an increase in risk with higher dust exposure was established only among men with cate- 
Table 6 Estimates of logistic regression coefficients, and associated tests of statistical significance, based on all data where men had category 1 or more CWSP; and all occurrences of $P M F$, with a $10 \%$ random sample of non-occurrences, among intervals with CWSP category 0

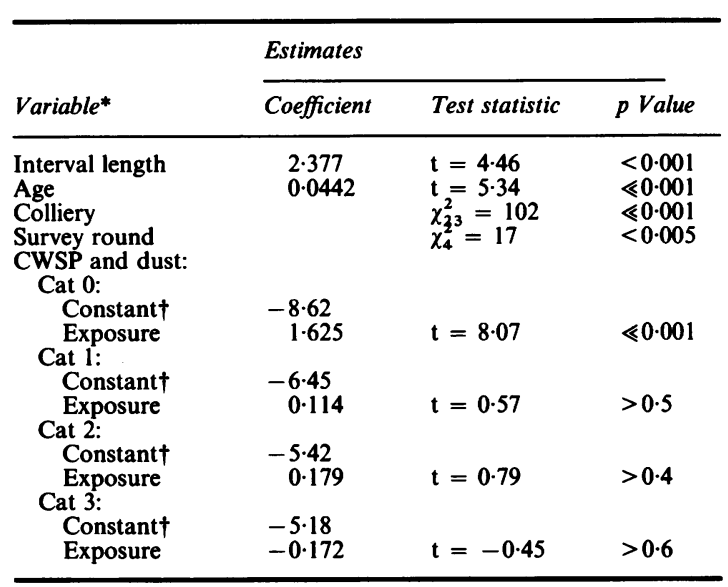

*Units of measurement, and transformations used in the analyses, as in table 5 .

†The constants shown refer to incidence from PFR 1 at colliery W, for a 45 year old man with $200 \mathrm{ghm}^{-3}$ exposure.

gory 0 , the relative risks in this group are always lower than among similarly exposed men with category 1 or more CWSP.

Table 6 also shows that the relation between age and PMF incidence was still evident even when CWSP category was taken into account. The relative risk was estimated, as before, at about 1.5 for each additional 10 years in the ranges ( 25 to 65 years) experienced by the men studied. This estimate was

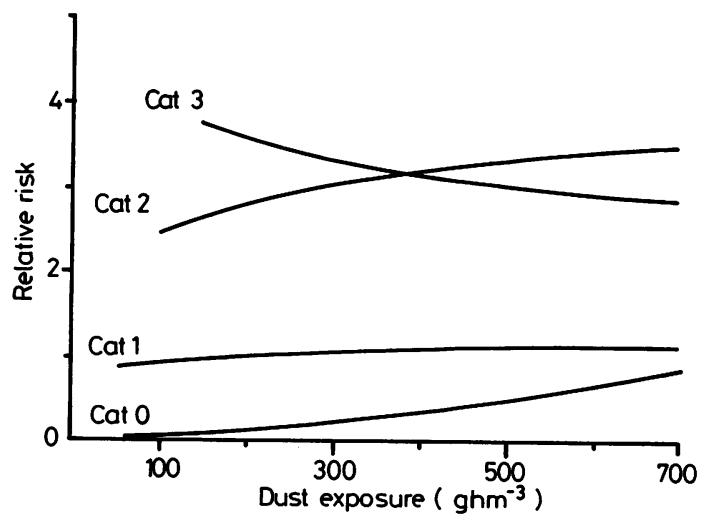

Fig 1 Risks of PMF incidence over a five year period at various levels of cumulative dust exposure and attained $C W S P$ category relative to the risks for a miner with category $1 \mathrm{CWSP}$ and $200 \mathrm{ghm}^{-3}$ exposure, using coefficients in table 6.
Hurley, Alexander, Hazledine, Jacobsen, Maclaren

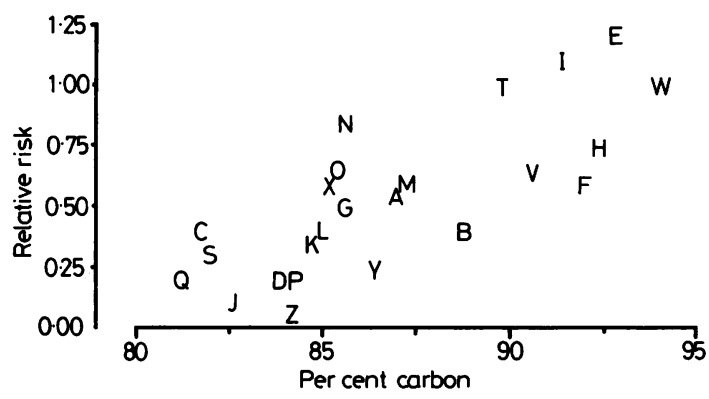

Fig 2 Relation between per cent carbon and colliery specific risks of PMF over a five year period, relative to risks at colliery $W$, adjusting for age, dust exposure, CWSP category, and PFR survey round (see table 6).

consistent among men from each simple pneumoconiosis category.

The survey specific influences were also largely unaltered. Risks at PFR 2, 3, 4, and 5 relative to PFR 1 were now estimated as $0.81,0.48,0.75$, and 0.55 respectively, whereas concurrent exposure again appeared unrelated to incidence once other influences had been considered $(t=-0 \cdot 12)$.

Finally, there were again substantial differences in relative risks between collieries. Further investigation. summarised in fig 2 , showed that these were clear related to, but not entirely explained by, collie related differences in the carbon content of the coar. Detailed within-category analyses showed that the association of colliery differences with carbon content was obscured among men with categories 2 or 3 CWSP, possibly due in part to the smaller numbers of intervals available for study.

\section{Discussion}

Earlier studies from the PFR gave grounds for hope that the role of dust exposure in the development of PMF could be clarified. ${ }^{91112}$ A relation between exposure to dust and incidence of PMF has indeed been identified and described convincingly. Before considering the substantive findings, however, we discuss the reliability of the results and the data on which they are based.

\section{RELIABILITY OF RESULTS}

This was a large scale study, with data from more than 30000 coalminers, and a wide-ranging one, including substantial numbers of men from all the coalfields in Britain. Long term employment as a 0 coalminer was not a requirement for inclusion: it was sufficient that a man had participated in two succes- $\stackrel{\mathscr{?}}{?}$ sive five yearly medical surveys while employed as a coalminer. On the other hand, results refer only to the 
men's experience while still working as coalminers and the attack rate of PMF in ex-miners is relatively high. ${ }^{11}$ It appears, however, that the relation between dust exposure and PMF incidence is essentially the same in miners and ex-miners, ${ }^{28}$ and so the exposureresponse relations of the present study may well be applicable to ex-miners also.

Similarly, we think that the estimated exposureresponse relations are relevant to current dust conditions though the study data refer to a period from 1953 to 1978. The prevalence of PMF among coalminers was declining in that period and has continued to decline since, ${ }^{29}$ due to reductions in dust concentrations, better provision for men with simple pneumoconiosis, and earlier retirement from the industry among other factors. It is not clear whether the relation of PMF to dust exposure and to other factors was also changing. We think it likely that it has not, since estimates of exposure-response relations are more stable under changing conditions than simple estimates of prevalence or incidence.

Estimates of exposure were based on comprehensive environmental monitoring linked with detailed records of time worked. We think, however, that exposures experienced by men at some collieries before the research proper have been underestimated, ${ }^{47}$ and they constitute an important part of the exposure data for the present study. Nevertheless, PFR dust exposure estimates which include a preresearch component have been related successfully to respiratory health in a wide variety of studies, ${ }^{34711-131830}$ and they have highlighted issues that could not be examined by radiological category and time worked, the main surrogate measures of exposure. For example, analyses of lung function ${ }^{30}$ and the present study both showed that exposure to dust is related to respiratory health even among men with CWSP category 0 . And exposure, which is concentrated weighted time, relates more directly than time itself to presence or absence of CWSP category 2 or more. ${ }^{7}$ Thus we are confident that the association of PMF to exposure as shown in the present study is a real relation and we further believe that the exposures are sufficiently reliable that the quantitative estimates of this relation are trustworthy also.

Such a conclusion depends also on the reliability of classifications of PMF. The readings were carried out by the National Coal Board's group of medically qualified specialists in radiological classifications whose shared experience helped to maintain consistency of classifications during the course of the research, despite changes in the ILO standards for film readings and in the composition of the group itself. Most of the intervals at risk, and most of the cases of PMF, refer to the earlier part of the research when classifications required the agreement of at least two doctors of the group. It was in this calendar period also that the need to distinguish PMF from tuberculosis was most required. Subsequent classifications may be less exact since they were for clinical rather than for epidemiological purposes and each reading involved one doctor only, but it was not feasible to have the films reread. Classification errors are therefore more likely in the present investigation than in other PFR film reading studies ${ }^{791120}$ but the estimates of exposure-response relations are not necessarily biased as a result. Since different doctors classified films from different collieries, colliery related differences in exposure-response include a component due to inter-reader differences in film classifications.

Consider, finally, the epidemiological approach adopted. We have been considering a longitudinal study with a discrete response, an area where development of statistical methods is still taking place. A recent review, however, recommends an approach similar to that adopted here. ${ }^{31}$ The epidemiological and statistical methods used are analogous to those for mortality studies but with first notification of PMF as the response of interest. More advanced methods of mortality analysis, ${ }^{32}$ requiring information on exact date of death, were not used since a corresponding exact date of occurrence of PMF may not be meaningful, and in any case is not available in practice. We considered using a complementary loglog rather than logistic regression model to express the relations of predisposing factors to incidence. The choice could have been important if the interval length had varied more and included some short study periods. The bulk of the data, however, did refer to periods of about five years duration, limited analyses using both frameworks gave similar answers, and the logistic approach was adopted since it seems adequate and is well known.

\section{SUBSTANTIVE FINDINGS}

Against this background of the strengths and limitations of the data and the methods of analysis, we now consider the substantive findings from the present study.

As in previous studies, there were wide differences in PMF risks associated with simple pneumoconiosis. $^{8-11}$ We found a threefold to fourfold increase in PMF risks in coalminers who develop category 2 or 3 CWSP, as compared with those who have only category 1 . This testifies again to the value of persisting with well established, and effective, ${ }^{29}$ occupational hygiene and medical surveillance measures aimed at avoiding exposures to dust that may result in these more severe categories of simple pneumoconiosis.

But the data show also that PMF attack rates in 
working miners with only category 1 simple pneumoconiosis have been about 44 per 1000 over five years, on average. This is three or four times higher than estimates from earlier large scale studies in the British coalfields ${ }^{910}$ and similar to that reported recently in a smaller study of ex-miners. ${ }^{11}$ The finding reaffirms the need to continue with the policy which requires that dust concentrations underground be minimised at all times, in order to reduce further the incidence of even early signs of pneumoconiosis. ${ }^{1011}$

Differences in the CWSP category specific risks of PMF incidence confirmed indirectly the central role of mixed dust exposure in the development of the disease. The main objective, however, was to study directly the relation between exposure to dust and subsequent, short term incidence of PMF. The results showed that risks of an attack of PMF were systematically higher among men with higher exposure to mixed dust, not only in the study group as a whole but in almost every combination of age group and colliery where an attack had occurred (table 2). The statistical significance of the association was correspondingly clearcut. In our view the central role of dust exposure has been shown convincingly.

The argument for minimising dust levels, irrespective of whether they are approaching statutory control limits, is strengthened further by the results from miners with category 0 CWSP who formed the clear majority of those studied (table 3 ). Note that category 0 covers a range of radiological appearances, including some with small shadows that are not profuse enough to justify classification as category 1 . Although the average PMF attack rate among these men was relatively low, we have shown for the first time that the PMF risks in this group increase clearly and systematically with increasing exposure to dust.

This result is especially important because of the large numbers of men at risk. ${ }^{10}$ Thus despite a crude rate of only two attacks per 1000 men over approximately five year periods, one in five of all the occurrences observed in our study were experienced by miners with category 0 . There were, however, no new attacks among men with category 0 during intervals starting at PFR 4 or later, although such intervals comprised about $13 \%$ of the observations available. This seeming anomaly merits investigation, since our data suggested average exposures of roughly similar magnitudes for men at the five surveys.

It is interesting also to note the absence of any positive association between lifetime dust exposure and incidence of PMF once simple pneumoconiosis categories 1, 2, or 3 had been attained. We interpret this result as indicating that, whereas the chances of getting CWSP are well known to be dust related, ${ }^{7}$ once CWSP is established it is the fact of simple pneumoconiosis, rather than the amount of dust exposure
Hurley, Alexander, Hazledine, Jacobsen, Maclaren $\frac{\complement}{\bar{z}}$ necessary to cause it, that is related to the probability of a subsequent attack of PMF. The suggestion that PMF risks were highest among those who had? attained category 3 CWSP with relatively low $\overrightarrow{\vec{c}}$ exposures is consistent with the view that advanced $\frac{?}{\circ}$ simple pneumoconiosis in such men indicates their particular susceptibility to lung disease.

Exposures to mixed dust experienced during the $\frac{{ }_{0}}{\sigma}$ five year observation periods were small relative to 2 the cumulative exposures experienced before the peri- $\infty$ ods studied, and they did not have any demonstrable $\overrightarrow{0}$ effect on concurrent incidence of PMF. Such $\overrightarrow{ }$ exposures were not irrelevant, however. They led to $\vec{\omega}$ higher cumulative exposures in subsequent periods for the men concerned, thereby increasing the risks of $\frac{\mathbb{}}{3}$ a PMF attack among men with category 0 radiographs. Higher cumulative exposures did not increase similarly the short term risks of incidence for men $\vec{\circ}$ with category 1 or more CWSP, but we know froms other studies that among men showing early signs of simple pneumoconiosis, further dust exposure is related positively to the progression of CWSP, and $\vec{P}$ hence indirectly to later risks of PMF. ${ }^{33}$

The study of age and of colliery related differences $\frac{O}{0}$ was subsidiary to the main task of describing the effect of dust exposure. The results were nevertheless $\vec{\varphi}$ interesting and may be important practically. The o risks of PMF incidence were higher in older men, haQ ing adjusted for both dust exposure and CWSP catgory. This association may simply indicate that agie increases lung susceptibility, or it may reflect othero effects - for example, the residence time of dust in the lung. In principle PFR data could be used to 2 differentiate between various possibilities, but to date $\overrightarrow{\hat{O}}$ we have not attempted to do this.

Colliery or regional variations within Britain in the incidence and prevalence of PMF are wel[ known. ${ }^{91029}$ One useful result from the present studyo is that the colliery related differences in risks do not $\frac{\Phi}{3}$ simply reflect differences in dust exposure, age, and 0 simple pneumoconiosis. Having adjusted for these 3 . influences, risks of PMF incidence varied between collieries by a factor of 20 or more. These variations $₹$ were related clearly to the percentage of carbon in theo coal, especially among men who did not have advanced simple pneumoconiosis. Dust suppressiono may therefore be particularly necessary at collieries where the per cent carbon in the coal is high.

Clearly, however, a long term strategy for the elim- $N$ ination of PMF requires that dust suppression must N్ట be maintained at an intensive level also at other pits. $\sigma$ In the first place the wide colliery related variations in the incidence of PMF were only partly explicable in $\frac{0}{\Phi}$ terms of the carbon content. There remain unexplained variations, even between collieries in the same region. Secondly, the carbon content of the coalo 
was not obviously related to PMF risks among men with categories 2 or 3 simple pneumoconiosis, and further, the association between the carbon content of the coal and incidence of simple pneumoconiosis is not strong. ${ }^{7}$

\section{CONCLUSIONS AND IMPLICATIONS}

Our main conclusion is that dust exposure is the most important single factor determining PMF risks. It acts in two ways. Firstly, men with higher exposures to dust are more likely to suffer from simple pneumoconiosis, and those who have attained not only CWSP categories 3 and 2, but category 1 also, are at higher risk of PMF. Secondly, among men with CWSP category 0 (the great majority of miners in Britain) PMF risks are clearly and systematically higher among men with higher exposures to dust. It follows that minimising of exposures to dust is the only sure way of controlling and eliminating PMF.

The main strategy for controlling exposures to dust is to minimise workplace respirable dust concentrations. Estimates of the risks of developing PMF over a working life at various concentrations of respirable dust are therefore especially useful in guiding policy to prevent the disease. Results from the present study of short term incidence of PMF may be extended to estimate the long term risks of developing the disease. Preliminary estimates have been reported ${ }^{34}$ and are being refined; further details will be described in another paper.

A complementary approach to the prevention of PMF is to identify, and provide special protection for, the few men most likely to react adversely to dust exposure. This requires consideration of additional factors such as smoking habit, physique, and respiratory symptoms. Their role in the development of PMF has also been studied recently; detailed results will be reported in another paper. The main implications for occupational health have been summarised in an article that concentrates on the statistical methodology used. They do not suggest that those at greatest risk can be identified easily. ${ }^{35}$ We therefore think that the only secure strategy currently available for reducing and ultimately eliminating PMF is to continue to minimise and maintain strict control of dust concentrations underground.

This study was supported by the European Coal and Steel Community and by the National Coal Board in Britain. We acknowledge in addition the contribution of all who participated in the Pneumoconiosis Field Research, including many colleagues past and present at the Institute of Occupational Medicine, without whom this study would have been impossible.

\section{References}

1 Gilson JC, Hugh-Jones P, Oldham PD, Meade F. Lung function in coalworkers' pneumoconiosis. London: HMSO, 1955. (Medical Research Council special report series No 290.)

2 Carpenter RG, Cochrane AL, Gilson JC, Higgins ITT. The relationship between ventilatory capacity and simple pneumoconiosis in coalworkers-the effect of population selection. Br J Ind Med 1956;13:166-76.

3 Rogan JM, Attfield MD, Jacobsen M, Rae S, Walker DD, Walton WH. Role of dust in the working environment in development of chronic bronchitis in British coalminers. $\mathrm{Br} J$ Ind Med 1973;30:217-26.

4 Miller BG, Jacobsen M. Dust exposure, pneumoconiosis, and mortality of coalminers. Br J Ind Med 1985;42:723-33.

5 Atuhaire LK, Campbell MJ, Cochrane AL, Jones M, Moore F. Mortality of men in the Rhondda Fach 1950-80. Br J Ind Med 1985;42:741-5.

6 Cochrane AL, Moore F, Thomas J. The radiographic progression of progressive massive fibrosis. Tubercle 1961;42:72-7.

7 Hurley JF, Burns J, Copland L, Dodgson J, Jacobsen M. Coalworkers simple pneumoconiosis and exposure to dust at 10 British coalmines. Br J Ind Med 1982;39:120-7.

8 Cochrane AL. The attack rate of progressive massive fibrosis. $\mathrm{Br}$ $J$ Ind Med 1962;19:52-64.

9 McLintock JS, Rae S, Jacobsen M. The attack rate of progressive massive fibrosis in British coalminers. In: Walton WH, ed. Inhaled particles III. Old Woking, Surrey: Unwin Bros, 1971:933-52.

10 Shennan DH, Washington JS, Thomas DJ, Dick JA, Kaplan YS, Bennett JG. Factors predisposing to the development of progressive massive fibrosis in coal miners. $\mathrm{Br} J$ Ind $\mathrm{Med}$ 1981;38:321-6.

11 Maclaren WM, Soutar CA. Progressive massive fibrosis and simple pneumoconiosis in ex-miners. Br J Ind Med 1985; 42:734-40.

12 Jacobsen M. Dust exposure, lung diseases and coalminers' mortality. Edinburgh: University of Edinburgh, 1976. (PhD thesis.)

13 Jacobsen $M$. The importance of epidemiology in research on pneumoconiosis. In: Epidemiology and technical and medical prevention of coal miners' pneumoconiosis, Industrial Health and Safety Seminar, Luxembourg, 1979. Luxembourg: Commission of the European Communities, 1981:5-25. (EUR 6879.)

14 Fay JWJ, Rae S. The pneumoconiosis field research of the National Coal Board. Ann Occup Hyg 1959;1:149-61.

15 Dodgson J, Hadden GG, Jones CO, Walton WH. Characteristics of the airborne dust in British coalmines. In: Walton WH, ed. Inhaled particles III. Old Woking, Surrey: Unwin Bros, 1971:757-82.

16 Case RAM, Lea AJ. Mustard gas poisoning, chronic bronchitis, and lung cancer. Br J Prev Soc Med 1955;9:62-72.

17 Berry $G$. The analysis of mortality by the subject-years method. Biometrics 1983;39:173-84.

18 Fay JWJ, Ashford JR. The study of observer variation in the radiological classification of pneumoconiosis. $\mathrm{Br} J$ Ind Med 1960;17:279-92.

19 International Labour Office. Meeting of experts on the international classification of radiographs of the pneumoconioses. Occupational Safety and Health 1959;9:63-9.

20 Jacobsen M, Burns J, Attfield MD. Smoking and coalminers' simple pneumoconiosis. In: Walton WH, ed. Inhaled particles IV. Oxford: Pergamon Press, 1977:759-72.

21 Watson $\mathrm{HH}$. The thermal precipitator. Transactions of the Institute of Mining and Metallurgy 1936-7;46:155-240.

22 Dunmore JH, Hamilton RJ, Smith DSG. An instrument for the sampling of respirable dust for subsequent gravimetric assessment. Journal of Scientific Instruments 1964;41:669-72.

23 Dixon WJ, Brown MB, Engelman L, et al. BMDP statistical software. Berkeley, LA: University of California Press, 1983. 
24 Cox DR. The analysis of binary data. London: Methuen, 1970.

25 McCullagh P, Nelder JA. Generalized linear models. London: Chapman and Hall, 1983.

26 Alvey NG, Banfield CF, Baxter RI, et al. Genstat-a general statistical program. Harpenden, Herts: Rothamsted Experimental Station, 1977.

27 Breslow NE, Day NE. Statistical methods in cancer research. Vol 1. The analysis of case-control studies. Lyon: International Agency for Research on Cancer, 1980.

28 Hurley JF, Maclaren WM. Factors influencing the occurrence of progressive massive fibrosis (PMF) in miners and ex-miners. In: Dodgson J, ed. Inhaled particles VI. Luxembourg: CEC (in press).

29 National Coal Board Medical Service: Annual reports, 1976-77 and 1983-84. London: National Coal Board.

30 Soutar CA, Hurley JF. Relations between dust exposure and lung function in miners and ex-miners. $\mathrm{Br} \mathrm{J}$ Ind Med 1986; 43:307-20.
Hurley, Alexander, Hazledine, Jacobsen, Maclaren

31 Muenz LR, Rubinstein LV. Markov models for covariate dependence of binary sequences. Biometrics 1985;41:91-102.

32 Cox DR, Oakes D. Analysis of survival data. London: Chapman and Hall, 1984.

33 Jacobsen M. Effect of further dust exposure among men with early and more advanced signs of simple pneumoconiosis. Edinburgh:? Institute of Occupational Medicine, 1979. (IOM report NoO TM/79/14.)

34 Hurley JF, Jacobsen M. Occupational hygiene implications of new results on progressive massive fibrosis in working? coalminers. In: Wheeler RW, ed. International conference on the health of miners. Cincinnati (OH): American Conference of Governmental Industrial Hygienists, 1986: 85-9. (Annals of the ACGIH; Vol 14.)

35 Maclaren WM. Using discriminant analysis to predict attacks of complicated pneumoconiosis in coalworkers. The Statistician $\vec{\omega}$ 1985;34:197-208.

\section{Vancouver style}

All manuscripts submitted to the $B r J$ Ind Med should conform to the uniform requirements for manuscripts submitted to biomedical journals (known as the Vancouver style)

The $\mathrm{Br} J$ Ind Med, together with many other international biomedical journals, has agreed to accept articles prepared in accordance with the Vancouver style. The style (described in full in Br Med J, 24 February 1979, p 532) is intended to standardise requirements for authors.

References should be numbered consecutively in the order in which they are first mentioned in the text by Arabic numerals above the line on each occasion the reference is cited (Manson ${ }^{1}$ confirmed other reports ${ }^{2-5} \ldots$.). In future references to papers submitted to the $\mathrm{Br} J$ Ind Med should include: the names of all authors if there are six or less or, if there are more, the first three followed by et al; the title of journal articles or book chapters; the titles of journals abbreviated according to the style of Index Medicus; and the first and final page numbers of the article or chapter.

Examples of common forms of references are:

1 International Steering Committee of Medical Editors. Uniform requirements for manuscripts submitted to biomedical journals. Br Med J 1979;1:532-5.

2 Soter NA, Wasserman SI, Austen KF. Cold urticaria: release into the circulation of histamine and eosino-phil chemotactic factor of anaphylaxis during cold challenge. $N$ Engl $J$ Med 1976;294:687-90.

3 Weinstein L, Swartz MN. Pathogenic properties of invading micro-organisms. In: Sodeman WA Jr, Sodeman WA, eds. Pathologic physiology: mechanisms of disease. Philadelphia: W B Saunders, 1974:457-72. 